\title{
Evaluation of Prophylactic Antibiotic in Caesarean Section
}

\author{
Ansari $\mathrm{N}^{1}$, Das $\mathrm{CR}^{2}$ Ansari $\mathrm{MA}^{3}$
}

\begin{abstract}
:
Introduction: Caesarean section is one of the most rewarding surgeries when performed in time and indication. The number of $\mathrm{C} / \mathrm{S}$ has been growing rapidly in the developing as well as developed world. Aims \& Objectives: Evaluation of prophylactic antibiotic in caesarean section. Methodology: This study was conducted in Nepalgunj Medical College Teaching Hospital, Kohalpur from June 2014 to September 2014. Group A consisted of 100 patient who were randomly allocated \& injection ceftriaxone $1 \mathrm{gm}$. I/V stat was given at the time of induction of anaesthesia ( 30 mins. before incision). Group B also consisted of 100 patients who were given 5 days antibiotics. Results: In post operative evaluation the infection rate were compared in both groups, group $A$ wound infection $2 \%$ and group B 3\%, Endometritis - group A 1\% and group B 2\%, UTI- group A 3\% and group B 4\%, Fever - group A $6 \%$ and group B 4\%. Conclusion: Single dose prophylactic antibiotic is comparable to multi dose antibiotic in this study. Since the single dose antibiotic is as efficacious as multi dose regime, it is advocated that single dose prophylactic antibiotic can be given in caesarean section as it is cost effective and as efficient as multi dose regimen.
\end{abstract}

Key words: Caesarean section, endometritis, fever, prophylactic antibiotic, UTI

\section{INTRODUCTION:}

Caesarean section is one of the most rewarding surgery when preformed in time and indication. The number of caesarean section has been growing rapidly in the developing as well as in developed world. The increase in routine caesarean section has been a global phenomenon. The concern has been expressed at the growing rate of caesarean section in some countries with some referring to it as emerging "global epidemic". In 1985 the WHO issued a consensus statement suggesting that there is no additional benefits associated with a caesarean section above $10-15 \%$. Caesarean section deliveries may have serious implication for the health of the women undergoing them. The risk of post-partum death is 3.6 times higher after caesarean section than after vaginal delivery.

Before the mid-nineteenth century surgical procedures commonly resulted in post-operative sepsis and death. In the 1860s, when Joseph Lister introduced the principles of antisepsis, the incidence of post operative infection fell markedly from $50 \%$ to $15 \%$. In the 1960 s, using an animal model, Burke demonstrated that if antibiotics were given before wound contamination, the rate of infection decreased ${ }^{1}$. Following caesarean delivery the maternal mortality and morbidity may result from a number of infections including endometritis, urinary tract infection (UTI) and surgical site

\author{
1. Dr. Nazmussaba Ansari \\ 2. Prof. C. R. Das \\ 3. Dr. Miraj Alam Ansari
}

\section{Address for correspondence:}

Dr. Nazmussaba Ansari

Department of Obstetrics \& Gyanecology

Nepalgunj Medical College Teaching Hospital

Kohalpur, Banke, Nepal

E-mail: drnazmussabaansari@gmail.com infection (SSI) which if deep rather than superficial, increases hospital stay and cost per case $\mathrm{c}^{2,3}$.

Prophylactic antibiotics have been shown to reduce the rate of surgical site infection. SSI accounts for $15 \%$ of nosocomial infections.The two more frequent complications of caesarean and hysterectomy surgeries are fever and SSI. Many studies have published in recent years stressing the need for antimicrobial prophylaxis both in hysterectomy and caesarean section. Although serious complications are uncommon, a literature survey demonstrated that prophylactic antibiotics significantly reduced the risk of endometritis and wound infection $^{4}$.

The prophylactic antibiotic in Nepalgunj medical college teaching hospital is not standardised and determined by the consultant incharge of the case. A prospective trial was performed to compare single dose pre-incisional antibiotic with regular antibiotic.

\section{Material \& Methods}

This is a comparative prospective hospital based study conducted in Nepalgunj Medical College Teaching Hospital, Kohalpur in the department of Gynaecology and Obstetrics from June 2014 to September 2014. Women who were scheduled to undergo caesarean delivery were enrolled in this trial. The caesarean was considered elective when the procedure was performed in the absence of labor and before rupture of membrane. Patients received information about objective concerning objectives of our trial prior to surgery and written consent was obtained. The study protocol was approved by the ethical committee of the hospital.

Patients were divided in 2 groups (Group A and Group B) each consisted of 100 patients. In group $A$, the patients were 
randomly allocated and injection Ceftriaxone 1gm. Intravenous stat. was given at the time of induction of anesthesia (30 mins. before incision). In group B, patients were given 1 day intravenous antibiotics (ampicillin and metronidazole) followed by oral for next 4 days. After surgery patients were assessed daily. Two main outcome of this study were fever and infection. Febrile morbidity was defined as temperature of $\geq$ $100.4^{\circ} \mathrm{F}$ recorded at least on two successive occasions 6 hours apart, excluding the $1^{\text {st }} 24$ hours of surgery. Infection of one or more sites were diagnosed by clinical symptoms, signs and laboratory tests. The infection included pelvic cellulitis, UTI, abdominal wound infection. Caesarean section group was followed up for the development of endometritis (i.e. fever, uterine tenderness and offensive lochia). All variables were analysed and data were entered in SPSS version 22 for descriptive and analytical study. A $p$ value of $<0.05$ was considered significant.

\section{RESULTS}

\begin{tabular}{|l|c|c|}
\hline Age (years) & Group A & Group B \\
\hline $\begin{array}{l}\text { No. patients mean } \\
\text { age in Years (SD) }\end{array}$ & $30.95 \pm 8.42$ & $28.7 \pm 5.44$ \\
\hline BMI in $\mathrm{kg} / \mathrm{m}^{2}$ (SD) & $21.9 \pm 2.22$ & $23.3 \pm 2.34$ \\
\hline
\end{tabular}

Table I: Charateristic of patients in two surgical groups

\begin{tabular}{|l|c|c|}
\hline & Group A & Group B \\
\hline $\begin{array}{l}\text { Mean duration of } \\
\text { operation mins. }\end{array}$ & 41 mins. & 45 mins. \\
\hline Mean blood loss ml. & 600 & 650 \\
\hline $\begin{array}{l}\text { Mean days of } \\
\text { catheterisatic }\end{array}$ & 1 & 1 \\
\hline
\end{tabular}

Table II: Risk factor for developing post-operative infection

\begin{tabular}{|l|c|c|c|}
\hline & Group A & Group B & p value \\
\hline Wound infection & 3 & 2 & 0.50 \\
\hline Endometritis & 1 & 2 & 0.50 \\
\hline UTI & 3 & 4 & 0.341 \\
\hline Fever & 6 & 4 & 0.26 \\
\hline
\end{tabular}

Table III: Incidence of post-operative infection

\section{DISCUSSION}

Many studies have supported antimicrobial prophylaxis guidelines. More over there is great variation in use of antibiotic prophylaxis, so in our study we used injection ceftriaxone $1 \mathrm{gm}$. for single dose in group $A$ and injection ampicillin and injection metronidazole for 1 day followed by oral antibiotics in group B. Following antibiotic prophylaxis, wound infection was found to be $3 \%$ in group $A$ and in contrast $2 \%$ in group $B$ with overall $P$ value 0.50 . Most of the authorities suggest prophylactic antibiotic should be considered for all elective caesarean deliveries in which the combined incidence

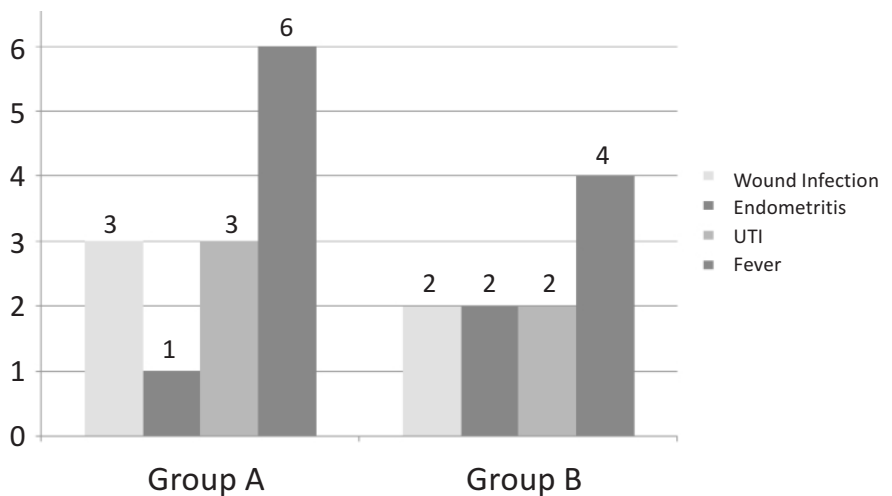

Figure 1: Bar chart showing the outcome of complications in both the groups

of endometritis and wound infection exceeds $5 \%{ }^{5}$. In this study, endometritis was $1 \%$ and $2 \%$ in group $A$ and $B$ respectively with overall $P$ value 0.50 . Similarly incidence of UTI was $3 \%$ in group $A$ and $2 \%$ in group $B$ with $P$ value to be 0.34 . Fever was $6 \%$ in group $A$ and $4 \%$ in group $B$ and $P$ value was 0.26 . The incidence of post- caesarean infection was similar when compared with other studies ${ }^{6,7}$. The prospective study confirms that single dose antibiotic prophylaxis had a beneficial effect on women undergoing elective caesarean section where as similar rate of complications were observed in multiple dose antibiotic for 5 days.

\section{CONCLUSION}

Single dose prophylactic antibiotic is comparable to multi dose antibiotic in this study. Since the single dose antibiotic is as efficacious as multi dose regimen, it is advocated that single dose prophylactic antibiotic can be given in caesarean section as it is cost effective and as efficient as multi dose regimen.

\section{REFERENCES}

1. Burke JF. The effective period of preventive antibiotic action in experimental incisions and dermal lesions. Surgery 1961;50:161-8.

2. Shetty J, Vyas N, Kumar P et al. Antibiotic prophylaxis for hysterectomy and cesarean section: Amoxicillin- clavulanic acid versus cefazolin. J Obstet Gynecol India. 2010; 60(5):419-23.

3. Smail Fl, Hofmeyr GJ. Antibiotic prophylaxis for cesarean section. Cochrane Database Syst Rev 2002: CD000933.

4. Chelmow D. Should patients undergoing low- risk $\mathrm{C} / \mathrm{S}$ receive antibiotic prophylaxis. Contemp Obstet Gynecol 2006;51:57

5. Chelmow D, Ruehli MS, Huang E. Prophylactic use of antibiotics for nonlaboring patients undergoing cesarean delivery with intact membrane: a meta analysis. AM J obstet Gynecol 2001;184:656-61.

6. Rouzi AA, khalifa $F$, Ba'aqeel $\mathrm{H}$ et al. The routine use of cefazolin in cesarean section. Int J Gynecolobstet 2000;69:107-12.

7. Yip SK, Lau TK, Rogers MS. A study on prophylactic antibiotics in cesarean sections-is it worthwhile? Acta Obstet Gynecol Scand 1997;76:547-9. 